\title{
The Effectiveness of Microsurgical Procedures inPatients with Upper Extremities Trauma
}

\author{
Albavera Gutierrez Eder MD ${ }^{1}$, Albavera Gutierrez Paloma Rosalva MD $^{1}$, Tolentino González \\ Christian S. MD², Flores Rodriguez Daniel $\mathrm{MD}^{3}$, Frias Lucio Yazmin MD ${ }^{4}$, Rodriguez \\ Rodriguez Carlos Eduardo $\mathrm{MD}^{5}$, Méndez Hernández Alberto Robles $\mathrm{MD}^{5}$, Lorenzo Hernández \\ Irving $\mathrm{MD}^{6}$, Luis Angel Medina Andrade $\mathrm{MD}^{7 *}$ \\ ${ }^{1}$ Plastic Surgery and Reconstructive Surgery, Hospital de Traumatología V.F.N. I.M.S.S., Mexico City, Mexico. \\ ${ }^{2}$ General Surgery Department, Hospital General de Zona \#47 “Vicente Guerrero”, Mexican Institute of Social \\ Security, México City. \\ ${ }^{3}$ Plastic Surgery Service, Hospital 20 de Noviembre, ISSSTE, México City, México. \\ ${ }^{4}$ Occupational Medicine Service, Hospital General de Zona \#32, Mexican Institute of Social Security, México \\ City. \\ ${ }^{5}$ La Salle University, General Surgery Service, Hospital Ángeles Metropolitano, México City, México. \\ ${ }^{6}$ General Surgery Service, Unidad Médica de Alta Especialidad Puebla, IMSS, México. \\ ${ }^{7}$ General Surgery Service, Hospital General de Zona \#30, Mexican Institute of Social Security, México City \\ *Corresponding Author: Luis Angel Medina Andrade.General Surgery Service, Hospital General de Zona \\ \#30, Mexican Institute of Social Security, México City, Meico,Email:buismedina_5@hotmail.com
}

\begin{abstract}
Background: The microsurgical techniques have evolved along the last decades, allowing excellent functional results in cases of reimplantation after amputations. The objective of this study is to evaluate the effectivity of those techniques in a trauma reference center in México.

Material and Methods: Patients with microsurgical procedures in the context of upper extremities trauma performed between March 01 of 2010 and August 01 of 2013 were included. The demographic and medical data were recorded and analyzed, identifying interest factors like type of lesion, level of lesion, ischemia time, lesion mechanism, type of magnification for repair and clinical evolution. Statistical analysis was performed with parametric statistics, central tendency and dispersion measures.
\end{abstract}

Results: From a total of 10 patients included, 9 were men (90\%) and 1 woman (10\%). About age, there were no patients from the first decade of life, 3 patients of the second, 3 patients of the third, 1 patient of the fourth and 3 patients of the fifth decade of life. The mechanisms of trauma reported include 1 patient with a sharp cut, avulsion in three patients, avulsion / tearing in 6 patients. The level if amputation according to the classification of Daniel and Terzis was 2 in two patients, 3 in six patients, 4 in one patient, and 6 in one patient. Other associated lesions were registered only in one patient. Ischemic processes were found in 7 patients with cold ischemia and 3 with warm ischemia. The time of ischemia vary from 2 to 9 hours, with a range between 0-2h in 1 patient; 3 to $4 \mathrm{~h}$ in 2 patients; 5 to $6 \mathrm{~h}$ in 5 patients; 9 to $10 \mathrm{~h}$ in 2 patients. Only 1 patient referred smoking. In five cases the patients were treated with magnifiers only and 5 with microscope assistance. Five patients presented a good evolution and five an unfavorable one.

Conclusions: There were lower cases than expected for a third level trauma center in the period of study, with favorable evolution under the worldwide levels reported. The patients with good evolution were younger and with a proximal amputation, the other factors were not significant for the evolution. More studies and a bigger simple are needed to elucidate the significance of other variables in the evolution.

\section{INTRODUCTION}

Since the beginning of XIX century the terminal -terminal vessel anastomoses was described with a fine suture; in 1912 the Nobel Prize Alexis Carrel describe the triangulation method for vessel anastomosis and the next year Höpfner reported the first experiments in reimplantation of extremities in dogs, constituting the first research in microsurgery ${ }^{1}$. The introduction in anticoagulation was a critic improvement in this field, with the Discovery of heparin by Jay McLean in 1916, and after that with the introduction of microscope by Nylen and Holmgren in Switzerland, From this point there 
exist four stages in the development of microsurgery: 1) early morning period (19501970),2) development period (1981-1997) 3)full maturity period (1981-1997) and 4)transition period from autogenous transplantation to allogeneic transplantation and regenerative medicine (1998-2007) [1-17].

The history of digital reimplants started more than 200 years ago when in 1814 William Balfour completes a finger autograft in a carpenter. After this description, many surgeons for more than 100 years treat the amputations with the use of a tubulized pedicled graft. In 1940 Harold Gillies suggest to remove the skin Surface of the finger before the autograft and add the tubulized graft, and in 1944 Stuart Gordon completes this technique with insensitive and non-functional results [13].

With the development of microsurgery the surgical techniques progress, so in the last 20 years, the microsurgical centers publish series of reimplantation with success in $80 \%$ of the patients. The success in those cases is secondary to the development of higher magnification surgical microscope, focus, and light; ultrafine sutures; small needles of high precision and other microsurgical isntruments [2], [4], [5], [13], [14].

Reimplantation is referred to reattach a segment of the body that was completely amputated, there is no conexión between the amputated segment and the body, and is the procedure of higher difficulty in reconstructive surgery [2], [3], [13], [14], [17].

The reimplantation is an expensive and complex procedure, that require prolonged surgical time, multiple surgeries and motivation for the rehabilitation by the patient for optimal results [3].

The incidence of hand trauma is variable between countries because is related to safety industrial standards. Constantly the amputations are more frequent in males compared to females about 5:1 to 6:1 and near 30 years of age, personal of industry, and in home in second place; the proximal phalanx is the most frequent amputation site and above the elbow the less frequent; with the non-dominant hand as the less frequent affected [13].

In an epidemiological review in the USA in 2011, they observe 9407 patients with amputations in upper extremities, 1361 treated with reimplantation, where success in younger patients was higher significantly, ages between 36 and 44 years old, and longer hospital stay in the reimplantation patients as well as higher cost [4], [7], [19].

The patients that assist urban hospitals and higher volume have a higher probability of reimplantation for the resources of these hospitals in equipment and qualified surgeons. This reference centers develop complex reimplantation of multiple fingers, hand, thoracic member and others [4], [7], [8].

The success is related with the family support, by the long periods of treatment and rehabilitation; the study and management must be given by a multidisciplinary team including hand surgery, psychiatry, physical medicine, occupational medicine, nursing, etc. [6], [7].

The initial management of the patients is in the emergency service according to the clinical state because in many cases the amputations are accompanied with other multisystemic lesions and must be treated according to ATLS guides, and only if the patients are stable and do not have associated injuries the reimplantation must be considered [6].

Factors that must be considered for reimplantation are the associated morbidity, possibility of survival, functionality of the reimplanted segment that must be equal or better than the previous, the total cost for patient or health service. The patients with a clean amputation are the ideal candidates, but these lesions are infrequent; the most frequent etiology is the crush and avulsion, diminishing the viability rate [2], [5], [6], [7], [9], [13].

Across the time the indications for reimplantation have not changed, including thumb amputation at any level, multiple fingers, through the palm, any segment in the child, amputation of the wrist, forearm, elbow and above this level, amputation distal to the insertion of the digitorum sublimis flexor; those are not necessary absolutely indications, but if there are other favorable factors the reimplantation must be considered, inclusive in avulsion lesions that require thumb shortening, fusión of metacarpophalangeal joint, with vein or nerve graft, and the results are frequently superior compared with other methods of reconstruction; in the zone II of Verdan area of flexors, zone III of Daniel and Terzis the digital reimplantation could have a comparable morbidity with the flexor tendons lesions [2], [5], [7], [13], [14], [15], [16], [18], [20].

The contraindications for reimplantation are relative, including severe injuries, severely crushed or shattered, amputation in multiple levels, amputation in a patient with severe 
previous diseases, with atherosclerotic vessels, amputation with prolonged hot ischemia $(>6 \mathrm{~h}$ in a major segment or $>12 \mathrm{~h}$ in a finger), amputation in mentally ill patients [2], [3], [5], [7], [9], [13], [14], [20].

The fingers amputated could be regarded at $4^{\circ} \mathrm{C}$ for 24 hours before reimplantation or $6 \mathrm{~h}$ with hot ischemia. According to the level of amputation, specialized material must be used for the reimplantation. The success of reimplantation is related to the age of patients, comorbidities, trauma mechanism, surgeon skills, postoperative management [2], [5], [18].

The Ishiwaka classification localize the level of amputation of the distal phalanx as follows: zone 1 , distal to the distal phalanx; zone 2, across the ungueal plate, retaining $50 \%$ of this plate; zone 3 , across the ungueal plate with less than $50 \%$ of the plate; zone 4 is proximal to the distal phalanx [16].

Initial surgical treatment must have a multidisciplinary team with experience and the required equipment for maximum quality. It begins with the administration of antibiotics, antitetanic vaccination, $x$ rays for the amputated segments; while a team is preparing the amputated segment for reimplantation with amplification equipment, with debridement, location of nerves and vessels; molding and shortening the bone, the Kirschner spike or plates are placed; the second team prepare the patient for surgical intervention, ideally with microscopes of high power [2], [5], [7], [15].

The regional anesthesia is preferred by the vasodilator effect. The sequence of reimplantation is influenced by the amount of muscle in the amputated segment and the time of ischemia, kind of lesion and the surgeon preference [2], [7], [13].

Post-surgical treatment includes anticoagulation and there no exist a determined protocol for all cases and centers by the lack of superiority of one protocol among the others. The first 2 days the risk of thrombosis is very high (80\%) and decrease to $10 \%$ after the third day. Conrad and Adams recommend the trans surgical use of a heparinized solution, a dose of heparin of 50-100 $\mathrm{U} / \mathrm{Kg}$ after the release of the clamps, and Dextran 40 at $0.4 \mathrm{~mL} / \mathrm{kg} / \mathrm{hr}$ to the 5 th day. Pederson recommends the application of Bupivacaine form an axillary catheter for 5 days to produce a chemical sympathectomy, the use of Chlorpromazine $25 \mathrm{mg}$ orally every 8 hours as a peripheral vasodilator for 3-5 days, and the use of acetylsalicylic acid $325 \mathrm{mg}$ orally each $24 \mathrm{~h}$ for the platelet antiaggregant effect for 3 weeks. Sabanpathy reports the use of a solution for irrigation during surgery prepared with 2000 heparin units, $20 \mathrm{cc}$ of lidocaine in 200cc of saline solution; $50 \mathrm{U} / \mathrm{Kg}$ of heparin intravenous dose after release of clamps and 5000 units of heparin in 500cc of saline solution for 24 hours and 5 days; avoiding the use of anticoagulation postsurgically in patients with proximal reimplant of elbow. Veravuthipakorn reports 40 patients without anticoagulation intra or post-surgical, with success in free flaps of $95 \%$ and $91 \%$ in reimplants [5], [7], [11], [15], [20]. There are no probes of the superiority of any anticoagulation scheme, and this fact supports that the surgical technique is the critic factor for survival [5], [7], [11].

The monitoring of perfusion is very important, many methods have been introduced but most of them are technically difficult and the continuous clinical evaluation is the standard reference for monitoring [7], [5], [13].

The reported mortality in some series is $0.4 \%$ without a difference in age, the related morbidity is about $0.6 \%$, complicating the course with pathologies like Deep venous thrombosis and pulmonary thromboembolism as the most common [9].

The only way to alleviate the vascular complications is the review of the anastomosis; the decision of surgical exploration is based on the lesion that produces the amputation and the surgical findings, with a successful index of 9$89 \%$ [5-14].

The serious complications are rare in reimplanted patients, the more frequent common include bleeding, infection and segment loss, the most common is venous insufficiency follow by arterial thrombosis in the first 24 hours. Those complications could be greater according to ischemia time, including ischemia-reperfusion phenomenon, leading to metabolic problems and sepsis [5], [11].

The traumatic lesions occupy the first places for work accidents and consultation in the medical services; it is estimated that 1,080, 000 workers suffer at least one lesion per year. The incidence is between 0.33 and 11 per 100 workers per year. The accidents are more frequent in patients younger than 40 years old, with wounds in $62.6 \%$, mild traumatism in $13.1 \%$, avulsions in $8 \%$, fractures in $4.8 \%$ and amputations in $1.1 \%$. 
In the USA between 2001,2004 and 2007 they reported 9,407 cases, and in 1,361 the completed reimplantation and between 1993 and 2002 a total of 16,128 reimplants of superior extremity. The majority of these procedures are performed in school hospitals, 81 to $89 \%$ of the cases according to statistics, and patients with health insurance. This procedure prolonged hospital stay with an average of 5.8 days (o-85 days) compared to 3.5 days (0-251) in patients without reimplantation. The total cost of those procedures is $\$ 42,561$ dollars in average, compared with $\$ 27,541$ dollars in patients without reimplantation.

In the services of general consultation of the Instituto Mexicano del Seguro Social (IMSS), 641,322 patients received consultation after traumatic lesions in the hand during 2007. It is estimated that the total cost of a traumatic lesion is $\$ 6,162$ American dollars. In 2010 the IMSS reported 506,528 work risk accidents (3.5 per 100 workers) (332,538 in males and 163, 999 in women); according to anatomic región a total of 104,432 were localized in hand $(78,190$ in men and 26,242 in women), accounting for $25.89 \%$ of the work accidents; with 2,961 amputations $(2,516$ in males and 445 females), and from those 1,956 men and 346 women were creditors to permanent disability.

According to the health cost of the IMSS published in 2012, the cost of attendance in patients with reimplantation after amputation of the upper extremity is about $\$ 27,664$ dollars.

For the previously exposed points, is very important to know the clinical evolution of the patients and consider the health cost of this procedures, because this would help us to give the patients the best management according to our situation. Is important to know that according to the literature, where the use of all the specialized equipment is mandatory for this procedures, the patient's opinion and the type of traumatic lesion plays an important role in the success of this procedure and the evolution after surgery.

The objective of this study is to know the effectivity of microsurgical procedures in patients with trauma of the thoracic members in V.F.N Trauma Hospital, IMSS, and the influence of multiple factors above the results (age, sex, mechanism of the lesion, amputation level, associated lesions, ischemia time, comorbidities).

\section{Material AND MethodS}

This is a retrospective, transversal, observational, descriptive study, that was developed in the external consult of Plastic and reconstructive surgery service and clinical file service of the Hospital de traumatología VFN. The period of study was from March 1, 2010, to August 1, 2013. The patients included must have a traumatic lesion in the thoracic member that requires a microsurgical technique for reconstruction. The data were collected from the clinical files of the Hospital de Traumatología VFN, from the Instituto Mexicano del Seguro Social (IMSS).

\subsection{Inclusion Criteria}

a) Patients with traumatic thoracic member lesion and complete file that underwent a microsurgical procedure for reimplantation in the Hospital de Traumatología V.F.N. I.M.S.S. in the period between March 1, 2010, to August 1, 2013.

\subsection{Exclusion Criteria}

a. Incomplete files

b. Lost of follow up after reimplantation

\subsection{Sample size}

The sample size considering a $\mathrm{p}=0.05$ for $\mathrm{a}$ descriptive study with a continuous variable

The sample was obtained by a non-probabilistic technique and convenience, selecting all the cases with the inclusion criteria in the mentioned period for the descriptive study of one variable, with a confidence interval of $95 \%$ is $\mathrm{N}=62$ patients. In this study and the period analyzed we have a total sample of 10 patients.

The data collection was completed in the files service where all the collection data sheets were filled, the data was collected in an Excel file and the statistical analysis was completed with descriptive statistics, central tendency measures and dispersión.

\subsection{Evolution}

After the microsurgical treatment, the viability of the affected segment was considered a success and the loss of those were considered unfavorable. This variable was nominal.

\subsection{Ethical Aspects}

This was a retrospective study analyzing files, without any risk for the patients included, totally 
confidential, without transgression of ethics rules or the general law of health, the rules for research in the hospital and according to the Helsinki amendment, codes and international laws for the good practices in research, and do not require informed consent.

\section{RESULTS}

Table1. Patients with thoracic member trauma that under went microsurgical procedures in the el HT VFN I.M.S.S.

\begin{tabular}{|c|c|c|c|c|c|c|c|c|c|c|}
\hline Patient & & 2 & 3 & 4 & 5 & 6 & 7 & 8 & 9 & 10 \\
\hline & Sex & $\begin{array}{l}\text { Age } \\
\text { (year) }\end{array}$ & $\begin{array}{l}\text { Traumamecha } \\
\text { nism }\end{array}$ & $\begin{array}{l}\text { Amputatio } \\
\text { n level }\end{array}$ & $\begin{array}{l}\text { Associate } \\
\text { d Lesions }\end{array}$ & $\begin{array}{l}\text { Type of } \\
\text { ischemia }\end{array}$ & $\begin{array}{l}\text { of Ischemia } \\
\text { a time } \\
\text { (hours) }\end{array}$ & $\begin{array}{l}\text { Comorbiditi } \\
\text { es }\end{array}$ & $\begin{array}{l}\text { Magnificatio } \\
\text { n material }\end{array}$ & Evolution \\
\hline 1 & 1 & 23 & 3 & 3 & 2 & 2 & 4 & 2 & 2 & 2 \\
\hline 2 & 2 & 24 & 3 & 2 & 2 & 1 & 6 & 2 & 2 & 2 \\
\hline 3 & 1 & 50 & 2 & 2 & 2 & 1 & 9 & 2 & 2 & 2 \\
\hline 4 & 1 & 40 & 2 & 3 & 2 & 1 & 4 & 2 & 2 & 1 \\
\hline 5 & 1 & 12 & 2 & 6 & 1 & 1 & 5 & 2 & 1 & 1 \\
\hline 6 & 1 & 46 & 1 & 3 & 2 & 2 & 5 & 2 & 1 & 2 \\
\hline 7 & 1 & 17 & 3 & 3 & 2 & 1 & 5 & 2 & 1 & 1 \\
\hline 8 & 1 & 20 & 3 & 3 & 2 & 2 & 2 & 1 & 2 & 1 \\
\hline 9 & 1 & 22 & 3 & 4 & 2 & 1 & 6 & 2 & 1 & 1 \\
\hline 10 & 1 & 50 & 3 & 3 & 2 & 1 & 9 & 2 & 1 & 2 \\
\hline
\end{tabular}

From the patients in studied 9 were men $(90 \%)$ and 1 woman (10\%) (Table 2).

Table2. The total number of cases and percentage of patients according to sex.

\begin{tabular}{|l|l|l|}
\hline Sex & Frequency & Percentage \\
\hline Women & 1 & $10 \%$ \\
\hline Men & 9 & $90 \%$ \\
\hline
\end{tabular}

By the range of age, the admissions vary form patients with 12 years-old to 50 years old, with a median of 30.4 years, an average of 23.5, mode of 50, range of 38 and standard deviation of 14.51. In the first decade of life there were no admissions, from the second decade 3 patients (30\%), from the third decade $3(30 \%)$; from the fourth decade 1 patient (10\%); from the fifth decade 3 patients (30\%). Table 3 .

Table3. Distribution by age in the studied patients.

\begin{tabular}{|l|l|l|}
\hline \multicolumn{1}{|c|}{ Age } & Frequency & Percentage \\
\hline $1-10$ years & 0 & $0.00 \%$ \\
\hline $.11-20$ years & 3 & $30.00 \%$ \\
\hline $.21-30$ years & 3 & $30.00 \%$ \\
\hline $.31-40$ years & 1 & $10.00 \%$ \\
\hline $41-50$ years & 3 & $30.00 \%$ \\
\hline
\end{tabular}

With respect to trauma mechanism we find a sharp cut in 1 patient (10\%); and avulsion in 3 patients $(30 \%)$, avulsion/tearing in 6 patients $(60 \%)$. Table 4.
A total of 10 patients were included with a background of thoracic member trauma and microsurgical procedures for reimplantation in the Hospital de Traumatología Victorio de la Fuente Narváez, in the period between March 01 of 2010 to August 01 of 2013, fulfilling the inclusión criteria (Table 1).
Table4.Trauma mechanism with frequency and percentages.

\begin{tabular}{|l|l|l|}
\hline Trauma mechanism & Frequency & Percentage \\
\hline Sharp cut & 1 & $10 \%$ \\
\hline Avulsion & 3 & $30 \%$ \\
\hline Avulsion / tearing & 6 & $60 \%$ \\
\hline
\end{tabular}

The level of amputation according to the Daniel and Terzis classification, without any level 1;2 patients with level 2, 6 patients in level 3, 1 patient in level 4, 0 patients in level 5 and 1 patient in level 6. Table 5.

Table5. Levels of amputation, frequency and percentage.

\begin{tabular}{|l|l|l|}
\hline Amputation level & Frequency & Percentage \\
\hline Level 1 & 0 & $0 \%$ \\
\hline Level 2 & 2 & $20 \%$ \\
\hline Level 3 & 6 & $60 \%$ \\
\hline Level 4 & 1 & $10 \%$ \\
\hline Level 5 & 0 & $0 \%$ \\
\hline Level 6 & 1 & $10 \%$ \\
\hline
\end{tabular}

With respect to the associated lesions, there were found only in $10 \%$ of the patients, the other $90 \%$ have a unique lesion. (Table 6).

Table6. Associated lesions, frequency and percentages.

\begin{tabular}{|l|l|l|}
\hline \multicolumn{1}{|c|}{ Associated Lesions } & Frequency & .Percentage \\
\hline Yes & 1 & $10 \%$ \\
\hline No & 9 & $90 \%$ \\
\hline
\end{tabular}


The type of ischemia was cold in 7 cases $(70 \%)$, and warm ischemia in 3 patients $(30 \%)$. Tabel 7.

Table7. Type of ischemia, frequency, and percentages.

\begin{tabular}{|l|l|l|}
\hline Type of ischemia & Frequency & Percentage \\
\hline Cold & 7 & $70 \%$ \\
\hline Warm & 3 & $30 \%$ \\
\hline
\end{tabular}

The time of ischemia was of 2 hours mínimum, with a máximum of 9 hours, with a range of 7 hours, mode of 5 . In the range of $0-2$ hours the frequency was $10 \%$; between $3-4$ hours the frequency was $20 \%$; 5 to 6 hours $50 \%$ and $9-10$ hours $20 \%$ (Table 8 ).

Table8. Ischemia time

\begin{tabular}{|l|l|l|}
\hline \multicolumn{1}{|c|}{ Ischemia time } & Frequency & Percentage \\
\hline $0-2 \mathrm{hrs}$ & 1 & $.10 \%$ \\
\hline $3-4 \mathrm{hrs}$ & 2 & $20 \%$ \\
\hline $5-6 \mathrm{Hrs}$ & 5 & $.50 \%$ \\
\hline $7-8 \mathrm{hrs}$ & 0 & $0 \%$ \\
\hline $9-10 \mathrm{Hrs}$ & 2 & $.20 \%$ \\
\hline
\end{tabular}

Only $10 \%$ of the cases present comorbidity associated with the amputation and was smoking, the other $90 \%$ does not present any comorbidity. Table9. Comorbidities, frequency, and percentage

\begin{tabular}{|l|l|l|}
\hline \multicolumn{1}{|c|}{ Comorbidities } & Frequency & Percentage \\
\hline Yes & 1 & $10 \%$ \\
\hline No & 9 & $90 \%$ \\
\hline
\end{tabular}

With respect to the magnification material, the plastic surgeons work with magnification lenses in 5 occasions and microscope in 5 patients $(50 \%)$ (Table 10).

Table10. Magnification material, frequency and percentage

\begin{tabular}{|l|l|l|}
\hline $\begin{array}{l}\text { Magnification } \\
\text { material }\end{array}$ & Frequency & Percentage \\
\hline Magnification lenses & 5 & $50 \%$ \\
\hline Mycroscope & 5 & $50 \%$ \\
\hline
\end{tabular}

The follow up during hospitalization and evolution was qualified as favorable in 5 patients $(50 \%)$, and unfavorable in 5 more $(50 \%)$. Table 11.

Table11. Patients evolution

\begin{tabular}{|l|l|l|}
\hline \multicolumn{1}{|c|}{ Evolution } & Frequency & Percentage \\
\hline Favourable & 5 & $50 \%$ \\
\hline .Unfavorable & .5 & $.50 \%$ \\
\hline
\end{tabular}

\section{DISCUSSION}

There is limited evidence for the best indications in the decision of reimplantation after the trauma of thoracic member. The management and publications of reimplantation are originated from case series and recommendations based only in surgeon's experience. Some articles suggest that reimplantation must be treated in childhood and when the level of amputation is in the wrist or forearm. Contraindications include any lesion that compromises the patient life, important chronic disease, psychiatric major disease, prolonged warm ischemia or the possibility of worsening the function.

In our retrospective and observational study, the patients treated after thoracic member amputation with microsurgical techniques in the Trauma Hospital "Victorio de la Fuente Narvaez", the lesions were more frequent in males, with a male: female ratio 9:1, percentage of $90 \%$, corresponding with the higher frequency of workers and operators of heavy machinery in the male sex. In the age we found that lesions were more frequent in patients from 11 to 50 years, corresponding with similar previous reports. This population corresponds with economically active population, meaning an important social and economic impact for this patient treatment. The international reports mention the age as a prognostic factor, ad our study confirm that the patients under 22 years presented a more favorable evolution, considering too that the level of amputation in those patients were proximal, with more level 3 lesions, and according to the literature the proximal amputations corrected by microsurgery obtain better results, for the bigger diameter of vessels and the inflammation of the intimate layer is not obstructive, with an easier to perform surgery for surgeons maybe with less specialization compared with the required abilities for a more distal amputation.

Other older patients presented less favorable evolution, with some factors that could be involved in those results like other comorbidities associated, atherosclerosis, more intense response to trauma from the intima layer, and worse quality of tissues.

In relation with the mechanism and type of lesion, the avulsions and tearing lesions have negative factors for success of the reimplantation procedure with microsurgery, and sometimes inclusive are considered contraindications, but in our study 5 of the patients presented this kind of lesions and good evolution; for this reason, more studies are needed to evaluate other factors that can influence the results.

One of the main factors influencing the favorable evolution of the patients is the transfer of amputated segments (cold ischemia), and analyzing the results, $20 \%$ of the patients with favorable evolution did not have cold ischemia, 
for this we can suspect that this is an important factor in the evolution, and the time of evolution of less than 4.4 hours according with our results.

The previous is similar to the international literature that mentions that with less time of transfer the intervention, evolution, and prognosis are better. Since 1920 when the microscope was introduced by Nylen and Holmgren the microsurgery born, and actually there exist many different instruments with different potency and specifications. These instruments are vital for the management, preparation and results in these patients, being a gold standard, but in expert hands the use of comfortable magnifiers could be useful depending of the anatomic site to treat; in our study the patients with favorable evolution were treated with magnifiers in 3 cases and microscope in 2 cases.

We found that in the 10 cases presented, only $50 \%$ have a favorable evolution, with younger patients, proximal level of amputation, cold ischemia during transfer, and only one with associated lesions, and lower time from accident to surgery in those patients with good results as reported in the literature, but with lower rate of success compared with other centers of microsurgery. Special focus must be maintained in the mechanism of trauma, that was not the ideal form reconstruction in many of the presented cases and the use of magnification devices instead of the microscope for the presented results.

\section{CONCLUSiOnS}

In the present study, the effectivity of microsurgical reimplantation in patients with trauma of the thoracic member was 50\%, between March 1 of 2010 and August 1 of 2013, this is inferior to international reports, with a success in 85 to $95 \%$ of the cases.

The associated factors with good evolution were similar to previous reported, including age, proximal amputation level, cold ischemia, less time since the accident and surgical repair. The age is a positive factor by fewer comorbidities, better tissue quality and better response to trauma.

The type of magnification didn't show influence in the results significantly, but other studies with bigger sample size are needed to clarify this point.

\section{REFERENCES}

[1] Tamai S. History of Microsurgery. Plast Reconstr Surg. 2009; 124: 282e - 294e.

[2] Green DP, Cirugía de la Mano, 5a ed. México, Editorial Marbán, 2007, Vol 2, Cap 45, pp 1569 $-1586$.

[3] Sebastian SJ. A Systematic Review of the Outcomes of Replantation of Distal Digital Amputation. Plast Reconstr Surg. 2011; 128: $723-737$.

[4] Friedrich JB, Poppler LH, Mack CD, Rivara FP, Levin LS, Klein MB. Epidemiology of Upper Extremity Replantation Surgery in the United States. J Hand Surg. 2011; 36A: 1835 - 1840.

[5] Pederson WC. Replantation. Plast Reconstr Surg. 2001; 107: $823-841$.

[6] Marchessault JA, McKay PL, Hammert WC. Management of the Upper Limb Amputations. J Hand Surg. 2011; 36A: $1718-1726$.

[7] Sabapathy SR, Venkatramani H, Bharathi R, Bhardwaj P. Replantation Surgery. J Hand Surg. 2011; 36A: $1104-1110$.

[8] Chen MW, Narayan D. Economics of Upper Extremity Replantation: National and Local Trends. Plast Reconstr Surg. 2009; 124: 2003 2011.

[9] Barzin A, Hernandez-Boussard T, Lee GK, Curtin C. Adverse Events Following Digital Replantation in the Elderly. J Hand Surg. 2011; 36A: $870-874$.

[10] Papanastasiou S. Rehabilitation of the Replanted Upper Extremity. Plast Reconstr Surg. 2002; 109: $978-981$.

[11] Buckle T, Hammert WC. Anticoagulation Following Digital Replantation. J Hand Surg. 2011; 36A: 1374 - 1376.

[12] Wang WZ, Baynosa RC, Zamboni WA. Update on Ischemia-Reperfusion Injury for the Plastic Surgeon: 2011. Plast Reconstr Surg. 2011; 128 : $685 \mathrm{e}-692 \mathrm{e}$.

[13] Chung KC, Alderman AK. Replantation of the Upper Extremity: Indications and Outcomes. J Hand Surg. 2002; 2: 78 - 94.

[14] Bastidas N, Cassidy L, Hoffman L, Sharma S. A Single-Institution Experience of Hand Surgery Litigation in a Major Replantation Center. Plast. Reconstr. Surg. 2011; 127: 284 - 292.

[15] Scheker L, Becker GW. Distal Finger Replantation. J Hand Surg. 2011; 36A: 521 - 528.

[16] Faivre S, Lim A, Dautel G, Duteille F, Merle M. Adjacent and Spontaneous Neurotization after Distal Digital Replantation in Children. Plast. Reconstr. Surg. 2003; 111: 159 - 165. 
[17] Lerman Z, Haddock N, Elliott R, Foroohar A, Levin S. Microsurgery of the Upper Extremity. J Hand Surg. 2011; 36A: 1092 - 1103.

[18] Rodríguez-Lorenzo A, Lin C, Lin C, Ching W, Lin Y. Replantation of a Degloved Hand With Added Arteriovenous Anastomoses: Report of Two Cases. J Hand Surg. 2009; 34A: $1864-$ 1867.
[19] Thoma A, Jansen L, Sprague S. Outcomes in Microsurgery. Plast. Reconstr. Surg. 2009; 124: $303-312$.

[20] Saint-Cyr M, Wong W, Buchel E, Colohan S, Pederson W. Free Tissue Transfers and Replantation. Plast. Reconstr. Surg. 2012; 130: $858 \mathrm{e}-878 \mathrm{e}$.

Citation: Albavera Gutierrez Eder et al. The Effectiveness of Microsurgical Procedures in Patients with Upper Extremities Trauma. ARC Journal of Surgery.2019;5(1):1-8.doi:dx.doi.org/10.20431/2455-572X. 0501001.

Copyright: () 2019 Authors. This is an open-access article distributed under the terms of the Creative Commons Attribution License, which permits unrestricted use, distribution, and reproduction in any medium, provided the original author and source are credited. 